\title{
HABERMAS, UM PENSADOR DE DOIS SÉCULOS: CONTRIBUIÇÕES FILOSÓFICAS
}

Delamar José Volpato Dutra ${ }^{1}$

\section{Resumo:}

O texto apresenta algumas contribuições filosóficas importantes de Habermas, considerando uma obra que abrange dois séculos. São destacadas as contribuições para a fundamentação da teoria crítica, para a fundamentação da ética e para filosofia do direito. Por fim, destaca-se a importância que a religião vem tomando nas reflexões de Habermas sobre a esfera pública, especialmente tendo em vista questões de bioética, como aquela da eugenia.

Palavras-chave: Habermas. Teoria crítica. Direito. Religião. Eugenia.

\section{HABERMAS, A THINKER OF TWO CENTURIES: PHILOSOPHICAL CONTRIBUTIONS}

\begin{abstract}
:
The text presents some important philosophical contributions made by Habermas, considering a work that spans for two centuries. Are highlighted the contributions to the foundation of critical theory, to the foundation of ethics and to the philosophy of law. Finally, it highlights the importance that religion has been taking in Habermas' reflections on the public sphere, especially in view of bioethical issues, such as that of eugenics.
\end{abstract}

Keyword: Habermas. Critical theory. Law. Religion. Eugenics.

\section{Introdução}

Habermas viveu o bastante para ser um pensador de dois séculos. O texto pretende mostrar algumas contribuições filosóficas do autor para os dois séculos que foram objetos de sua reflexão. No século XX, um dos pontos importantes de sua obra foi a fundamentação da teoria crítica. Um esforço que vem desde as suas primeiras obras, passando pela Teoria da ação comunicativa e chegando a Direito e democracia. Isso inclui destacar as conexões com a moral e com o direito. A sua obra do século XXI inaugura-se com o sugestivo Era de transições, cuja parte VII tem como título Jerusalém, Atenas e

1 Graduado em Filosofia (UCS) e em Direito (UFSC), doutor em Filosofia pela UFRGS, com estágio de doutorado na Université Catholique de Louvain, Bélgica. Fez pós-doutorado na Columbia University (New York) sobre a relação entre Dworkin e Habermas. Fez também pós-doutorado na Aberystwyth University (País de Gales, Reino Unido) sobre o tema "Habermas's Critique of Kant and Hobbes". É professor titular da Universidade Federal de Santa Catarina, com atuação na graduação, no Programa de pós-graduação em Filosofia (nota 6) e no Programa de Pós-Graduação Interdisciplinar em Ciências Humanas (nota 5). É pesquisador do CNPq desde 1999. Orcid: http://orcid.org/000-0002-3738-7865. E-mail: djvdutra@yahoo.com.br. 
Roma. Se a tônica do século XX foram as agruras da teoria crítica, a tônica do século XXI pode ser considerada a religião, levada ao centro da reflexão filosófica pelo atentado de 2001, em Nova Iorque. Com efeito, Entre naturalismo e religião vem a lume justamente em 2005.

\section{Fundamentação da teoria crítica}

No nonagésimo aniversário de Habermas, depois de quase um século de vida e de reflexões que aconteceram durante dois séculos, cabe a pergunta pelas contribuições filosóficas em cada um dos mesmos. Quais seriam elas? Na época em que vieram a lume as suas primeiras obras, na segunda metade do século XX, havia uma discussão se o que Habermas fazia era Filosofia ou Sociologia. Essa parece uma discussão superada para a nova geração de leitores. De todo modo, a perspectiva da fundamentação influenciou o modo como muitos leram Habermas no Brasil naquela época, na esteira da recepção feita por Almeida, em relação à teoria da verdade, Gianotti em relação à racionalidade comunicativa, Stein em relação à crítica à metafísica, dentre outros. ${ }^{2}$

Essa discussão realmente não compõe mais o cenário das publicações atuais, porém, ela permanece como pano de fundo, algo dado como garantido. Ainda assim, há questionamento recente desse ponto específico, e.g., aquele feito por Steinhoff ${ }^{3}$. Para se ter uma ideia do cenário da época, basta lembrar que havia o predomínio da filosofia analítica da linguagem com inspiração no primeiro Wittgenstein, aquele do Tractatus, cuja tônica era a defesa das proposições da ciência como sendo as únicas portadoras de valor de verdade, o que implicava uma crítica radical, não só da metafísica, mas também da ética, da estética, da filosofia política, bem como de outras áreas da Filosofia. Sabe-se que tal cenário começou a mudar com a publicação de Uma teoria da justiça de Rawls em 1971. Esse contexto é que poderia explicar, no início dos anos setenta, as

2 REPA, Luiz Sérgio. Reconstrução racional, argumento transcendental, fundamentação última: sobre o debate entre Habermas e Apel. Kriterion. N. 135, p. 741-758, 2016. Deveras, a questão da fundamentação foi tema da recepção de Apel e Habermas no Brasil. Pode-se ajuntar ao texto de Repa: CIRNE LIMA, Caros R. V. Sobre a contradição pragmática como fundamentação do sistema. Síntese. V. 18, n. 55, p. 595-616, 1991; DE OLIVEIRA, Manfredo Araújo. Sobre a fundamentação. Porto Alegre: EDPUCRS, 1993; HERRERO, F. Javier. A pragmática transcendental como "filosofia primeira". Veritas. V. 42, N. 4, p. 817-829, 1997; HERRERO, Javier. A razão kantiana entre o logos socrático e a pragmática transcendental. Síntese. V. 18, N. 52, p. 35-57, 1991.

3 STEINHOFF, Uwe. The Philosophy of Jürgen Habermas: A Critical Introduction. [K. Schöllner: Kritik der kommunikativen Rationalität: Eine Darstellung und Kritik der kommunikationstheoretischen Philosophie von Jürgen Habermas und Karl-Otto Apel]. Oxford: Oxford University Press, 2009.

n. 24

Setembro - Dezembro 2021

p. $54-66$ 
preocupações de Habermas e de Apel com a questão da verdade, bem como por que a ética discursiva nasceu como um programa de fundamentação. ${ }^{4} \mathrm{Um}$ dos textos fundantes da ética discursiva bem resume esse cenário:

Como já se sugeriu anteriormente, alguns pressupostos básicos da filosofia analítica moderna, diante de uma fundamentação da ética normativa, fazem-na parecer praticamente impossível. Procuraremos ter presentes os mais importantes dentre esses pressupostos:

1. Não se pode derivar normas de fatos (ou: de proposições descritivas não se podem deduzir proposições prescritivas e, portanto, quaisquer 'juízos de valor'). [...]

2. A ciência à medida que proporciona cognições conteudísticas, trata de fatos; por isso é impossível haver fundamentação científica de uma ética normativa" ${ }^{5}$.

3. O presente texto é uma leitura em função dessa problemática, principalmente. Há outros que destacarão a centralidade de obras distintas, as quais não serão aqui mencionadas diretamente, como, Mudança estrutural da esfera pública [1962] e $O$ discurso filosófico da modernidade [1985].

A tese de doutorado de Habermas foi sobre Schelling, intitulada $O$ absoluto e a história [1954], na qual ele reconstrói alguns aspectos materialistas de Schelling, que foram lidos por Habermas como uma espécie de antecipação do materialismo de Marx. A tese foi escrita em nove meses e defendida quando ele tinha 24 anos.

A narrativa da trajetória de pensamento, à qual Habermas se incorporou com essa tese, tem uma longa estirpe. Talvez, um dos primeiros dessa linhagem tenha sido Hobbes, que começou por separar o domínio político do domínio ético e o submeteu, via contrato, à forma jurídica. Ainda que Maquiavel possa ter os créditos dessa mudança de perspectiva, certamente, foi Hobbes quem o fez sob o ponto de vista dos direitos, justamente a determinação que veio a se tornar parte fundamental da gramática da justiça depois dele. Mesmo um autor como Honneth, ainda que tardiamente, alinhou-se a essa perspectiva no seu livro $O$ direito da liberdade [2011].

Rousseau foi um dos primeiros a se indispor com essa separação entre o público, o social, e o privado, determinado pela gramática dos direitos, sem, contudo, ter ele próprio podido deixar de considerar, de algum modo, tal separação e tal gramática.

4 HABERMAS, Jürgen. Da semântica formal à pragmática transcendental: a ideia original de Karl-Otto Apel. Ethic@. V. 19, N. 3, p. 487-517, 2020. [Dossiê O pensamento de Karl-Otto Apel. https://periodicos.ufsc.br/index.php/ethic/article/view/77949/45007].

5 APEL, Karl-Otto. Transformação da filosofia II: o a priori da comunidade de comunicação. São Paulo: Loyola, 2000 [1973], p. 427.

\begin{tabular}{|l|l|l|l|l|}
\hline Qovista Dialectus & Ano 10 & n. 24 & Setembro - Dezembro 2021 & p. 54 - 66 \\
\hline
\end{tabular}


Tanto é verdade que Schmitt afirma haver em Rousseau uma fachada liberal ${ }^{6}$, ou seja, um aspecto do privado que permanece, ainda que o núcleo do seu pensamento seja o caráter público, vale dizer, para Schmitt, o caráter homogêneo da vontade geral, que sobreporse-ia ao indivíduo, sem cerimonias. Nesse cenário, Kant, ainda que possa ser considerado um rousseauniano moderado no direito público, acabou por manter a separação hobbesiana entre a virtude e o direito em sua A metafísica dos costumes.

Hegel, não pôde deixar de vislumbrar, nessa separação, o predomínio do que ele chamou de sociedade civil. A bem da verdade, para ele, o Estado se tornara, na modernidade, incluso em Rousseau, um epifenômeno do âmbito privado. Como indício disso, basta lembrar da crítica que ele endereça ao tratamento jurídico que Kant oferta do casamento, como sendo escandaloso: "matrimônio (matrimonium), i. e., a ligação de duas pessoas de sexo diferente para a posse recíproca de suas propriedades sexuais ao longo de uma vida" [\$24]. Deveras, o que o Estado acaba por operar, em Hobbes, Locke, Rousseau, Kant, é a instituição e/ou proteção da propriedade privada, juntamente com a vida e a liberdade. Na sequência, tanto o direito abstrato [pessoa, posse, propriedade, contrato, ilícito], quanto a moralidade, serão subsumidos e conservados, por Hegel, em um novo domínio, aquele da eticidade. No demais, Hegel conseguirá vislumbrar, amiúde, eticidade na família, na sociedade civil, ou seja, no mercado [produção e consumo], bem como no Estado, este, aliás, uma determinação propriamente ética.

Marx, o leitor de Hegel, critica, desconstrói, essa caracterização ética do direito, da moral, do mercado e do Estado. Ele retira impiedosamente qualquer aura ética desses conceitos e vindica a interpretação que Hegel quisera questionar, contra o próprio empreendimento de Hegel. Dito claramente, família e Estado seriam tão somente epifenômenos do âmbito privado, do mercado, da economia capitalista. Marx mostra que na eticidade do Estado hegeliano não há nada mais do que as diretivas da grande propriedade fundiária. Para Marx, mercado, moral, Estado, família, não são determinações éticas, e, nem de longe, geram solidariedade, fraternidade, ao contrário,

\footnotetext{
6 "[...] a construção do Estado do Contrato social já continha dois elementos diversos, incorretamente juntos, lado a lado. A fachada liberal: fundamentação da legitimidade do Estado no livre contrato. Mas numa evolução posterior de seu estudo no desenvolvimento do conceito essencial da volonté générale evidencia-se que o verdadeiro Estado, segundo Rousseau, só existe ali, onde o povo é tão homogêneo, que a unanimidade passa a predominar. Pelo Contrato social, não devem existir partidos, nem interesses especiais ou diferenças religiosas, nada que separe as pessoas nem mesmo um sistema financeiro" [SCHMITT, Carl. A crise da democracia parlamentar. [Trad. Inês Lobbauer: Die geistesgeschichtliche Lage des heutigen Parlamentarismus]. São Paulo: Scritta, 1996 [1923], p. 15].
}

\begin{tabular}{|l|l|l|l|l|}
\hline Rovista Dialectus & Ano 10 & n. 24 & Setembro - Dezembro 2021 & p.54-66
\end{tabular}


geram alienação, exploração, pobreza, mesmo escravidão. Família, moral e Estado [aí incluído o direito], seriam meramente epifenômenos da alienação do trabalho, própria da economia capitalista.

Porém, no início do séc. XX, já tinha ficado claro que a crítica marxista precisava ser atualizada, melhorada. Isso, de fato, acontece com História e consciência de classe de Lukács de 1923, que incorpora os estudos de Weber sobre a perda de sentido e a perda de liberdade, um diagnóstico mais apropriado da modernidade. O conceito de reificação por ele desenvolvido visava a justamente dar conta desses problemas, mas Horkheimer e Adorno radicalizaram os efeitos da perda de liberdade e da perda de sentido pela incorporação da psicanálise. A Dialética do esclarecimento foi publicada em 1944 e marca quase um caráter derrotista da teoria crítica. Vale relembrar, o herói grego Ulisses parece ter ficado imobilizado na deformação dos ouvidos tampados pela cera. O trabalho parece despotencializado de qualquer positividade dialética. Eis, propriamente, a dialética negativa. É nesse ponto dos trabalhos de Horkheimer, Adorno e Marcuse, incluindo Benjamin, que Habermas adentra na teoria crítica.

\section{Habermas e a teoria crítica}

Nesse contexto, põe-se a primeira tentativa de Habermas de renovação da teoria crítica pelo viés da teoria do conhecimento. Conhecimento e interesse [1968] movimenta um interesse técnico para as ciências da natureza, um interesse prático para as ciências do espírito e um interesse emancipatório para a teoria crítica. Tais interesses teriam caráter transcendental e tornariam possível as várias áreas de conhecimento das quais dependeriam a reprodução da espécie humana, o trabalho e a interação.

A Teoria da ação comunicativa, 1981, marca a incorporação da filosofia da linguagem pela teoria crítica reconstruída por Habermas, que havia sido preparada por Trabalho e interação [1967], Christian Gauss Lectures ministradas em Princeton, 1971, Teorias da verdade, 1972, Transformação da Filosofia, de Apel, 1972-3, Pragmática universal, 1976.

Tem-se, durante a década de 70, em conjunto com Apel, o desenho da racionalidade comunicativa. Tratava-se, então, de analisar/reconstruir as condições de possibilidade dessa manifestação da racionalidade. A ação comunicativa, situada entre discurso e mundo vivido, tem como telos o entendimento, a validade [Geltung] como 
aceitação, já, o discurso tem como telos o consenso, a validade [Gültigkeit] no sentido da aceitabilidade. A prova apropriada para uma condição transcendental de possibilidade não seria uma prova demonstrativa. Com efeito, a questão é disputada desde os filósofos gregos, que mobilizaram uma prova como refutação. Aristóteles, no livro Gama da Metafísica usou com propriedade esse argumento. A prova do princípio de não contradição só pode ser por refutação, mostrando que mesmo aquele que viesse a negar o referido princípio, já o estaria utilizando. Para que a prova funcione, é preciso que o cético diga algo com sentido, ou seja, pratique um ato de fala, mesmo que seja a negação do princípio de não contradição. O cerne do argumento está em que para fazer uma proposição com sentido, negando o referido princípio, o cético teria que utilizá-lo. Descartes repetiu uma prova análoga com o cogito. Quem duvida que pensa, está pensado e, portanto, existindo. Apel e Habermas repetem algo análogo. De tal forma que aquele que pedir uma demonstração não a terá. O lado filosófico das provas por refutação é que elas, diferentemente das demonstrações, aportam uma prova de algo que não está propriamente explícito nas premissas, ou seja, tratar-se-ia de uma abdução mais do que de uma dedução. Vale lembrar que para Wittgenstein, todas as proposições da lógica dizem o mesmo, a saber, nada, pois não implicariam mais conteúdo nas conclusões do que haveria nas premissas. Com isso, ter-se-ia a primeira proposição da filosofia, ou seja, a refutação do cético teórico ${ }^{7}$. Dito claramente, não haveria como negar a pretensão de verdade das proposições, sob pena de autocontradição, como em Aristóteles.

No âmbito da filosofia teórica, tem-se a contribuição do conceito discursivo de verdade, formulado pragmaticamente. $O$ núcleo do argumento consiste na apresentação de uma concepção de verdade que une a versão epistêmica da verdade discursiva com a versão realista da verdade pragmática ${ }^{8}$.

Para a reconstrução aqui feita a propósito de Habermas, ele vai encontrar, junto com Apel, nas condições de possibilidade do significado como uso, ou seja, da comunicação, como que implícito, algo equivalente ao princípio de universalização. Com isso, tem-se um tipo de fundamentação da ética universalista que a resgata da sua gênese

7 Para uma visão divergentes desta apresentada ver STEINHOFF, Uwe. The Philosophy of Jürgen Habermas: A Critical Introduction. Oxford: Oxford University Press, 2009.

8 VOLPATO DUTRA, Delamar José. Da revisão do conceito discursivo de verdade em "verdade e justificação". Ethic@, v. 2, n. 2, 2003,p. 219-231.

\begin{tabular}{|l|l|l|l|l|}
\hline Qovista Dialectus & Ano 10 & n. 24 & Setembro - Dezembro 2021 & p. 54 - 66 \\
\hline
\end{tabular}


pela sociedade burguesa. Esta primeira contribuição: Habermas volta a dar um possível caráter emancipatório à ética, como bem aponta Apel:

Embora essa ética não possa deduzir o engajamento concreto na situação, ela pode conferir um parâmetro para a crítica, com base no qual o próprio engajamento pode se medir - seu êxito e seu fracasso. Essa necessidade não irá 'extinguir-se' com a 'burguesia', mas isso ocorrerá em todo caso quando a filosofia for 'superada' por sua 'efetivação') $)^{9}$.

A ética havia sido jogada fora por Marx com a água do banho. A ética já tinha sido desenhada nos textos da década de 70. Ela é operante na Teoria da ação comunicativa, muito embora, nesta obra, a fundamentação da teoria crítica tenha sido feita um passo atrás em relação à ética, a saber, na racionalidade comunicativa. De todo modo, será a perspectiva da fundamentação da ética que que lhe permitirá em 1986 nas Tanner Lectures recuperar também o direito, o que se consolida em 1992 com Faktizität und Geltung. Nisso, a sua segunda contribuição.

Em conexão com o direito, há uma diversidade de pontos a serem destacados. O primeiro deles é aquele referente aos direitos básicos para todos ${ }^{10}$, os quais nascem da interconexão entre os conceitos de forma jurídica e de princípio do discurso. A rigor, o princípio do discurso, vertido em uma forma jurídica, aparece como princípio da democracia. O princípio da democracia vem a lume contendo em si o Estado de direito, o que implica uma fundamentação do Estado de direito democrático. A democracia deliberativa fica a meio caminho entre uma versão mais republicana, como a de Arendt, e uma versão mais liberal, como a de Schumpeter. Vale destacar, nesse ponto, o tratamento que Habermas oferta da política. Ao contrário do que parece, a sua concepção de política tem como pano de fundo o seu tratamento por Hobbes e por Schmitt, portanto, ela considera as diferenças entre autoridade/dominação [Autorität/Herrschaft], poder [Macht]/violência [Gewalt]. O direito é chamado a mediar a relação entre a ação

9 APEL, Karl-Otto. Transformação da filosofia II: o a priori da comunidade de comunicação. São Paulo: Loyola, 2000 [1973], p. 489.

10 Steinhoff sustenta versão diversa: "[...] we are actually morally required not to treat all people with equal respect and concern. For one thing, the guilty can hardly have the same rights and moral standing as the innocent; and they certainly do not deserve the same treatment or to be treated "as equals." Therefore, a commitment to justice is not compatible with a commitment to liberal egalitarianism and equal respect and concern" [STEINHOFF, Uwe. Against Equal Respect and Concern, Equal Rights, and Egalitarian Impartiality. IN.: Do all Persons Have Equal Moral Worth: On "Basic Equality" and Equal Respect and Concern. Oxford: Oxford University Press, 2015, p. 172].

\begin{tabular}{|c|c|c|c|}
\hline Qevista Dialectus & Ano 10 & n. 24 & Setembro - Dezembro 2021 \\
\hline
\end{tabular}


comunicativa e a política nesse sentido amplo, já que é o direito que operará a ancoragem do Estado (e do mercado) no mundo vivido.

O segundo ponto a destacar, já desde a Teoria da ação comunicativa, é o seu diagnóstico das insuficiências do paradigma do trabalho como motor da emancipação. Com isso, o mercado, e nele o trabalho, passa a ser considerado como uma determinação sistêmica, neutralizado normativamente, que, pelo menos até o momento, aparece como uma realidade insuperável, que, não obstante, pode, ao menos por ora, ser domesticado, a fim de se adequar a determinações compensatórias, em decorrência de seus efeitos patológicos indesejados, pela via dos direitos sociais e da proteção ambiental. Esse é um ponto que permite a Habermas se contrapor à tese de Weber, seguida a não mais poder por Horkheimer e Adorno, de que a técnica e a ciência, na sua empreitada de dominação do mundo, implicariam necessariamente a dominação do homem pelo homem, determinando a perda do sentido e a perda da liberdade. Para o iluminista Habermas, a dominação da natureza constitui-se em um pressuposto conectado com a sobrevivência da espécie humana que não implica necessariamente a dominação do homem pelo homem, dentre outras razões porque seria possível vislumbrar uma sociedade que não seria mais tão dependente do trabalho ou, então, de uma dominação entre os humanos que já não poderia mais se basear preponderantemente na exigência do sacrifício. Eis a tese básica de Técnica e ciência como ideologia de 1968, que, aliás, parece cada vez mais se confirmar $^{11}$. Talvez, isso pudesse pô-lo em acordo com uma certa leitura de Marx, segundo a qual o aumento das forças produtivas implicaria o aumento das possibilidades emancipatórias, ao fim, conducente ao próprio comunismo, bem como pô-lo-ia em acordo com Hegel, para quem, no $§ 198$ da Filosofia do direito "A abstração do produzir torna o trabalho, além disso, sempre mais mecânico e, com isso, torna-o no fim apto para que o homem possa dele se retirar e deixar a máquina entrar em seu lugar." Dito claramente, o capitalismo não seria a única fonte de patologia. A ele dever-se-ia ajuntar aquelas do Estado, em fenômenos como o totalitarismo e o fundamentalismo.

Terceiro, o Estado é pensado como um sistema com uma linguagem própria e que, pelo menos por ora, também, permanece um outro elemento insuperável. Pareceria ser constitutivo da moral aplicada a seres racionais finitos a existência de certos déficits

11 ARAYA, Daniel. O que vem após a pandemia? Especialistas apostam no Renascimento Digital.https://forbes.com.br/colunas/2020/04/o-que-vem-apos-a-pandemia-especialistas-apostamno renascimento-digital/ [Acesso 19/04/2020].

\begin{tabular}{|c|c|c|c|c|}
\hline Qovista Dialectus & Ano 10 & n. 24 & Setembro - Dezembro 2021 & p. $54-66$ \\
\hline
\end{tabular}


que tornariam necessária à sua complementaridade pelo direito estatal nos itens da motivação, da organização e da cognição.

Quarto, o direito passa a ser visto como um dispositivo aproveitável para fazer, como sublinhado, a conexão, a ancoragem no mundo vivido, na racionalidade comunicativa, dos sistemas econômico e estatal. Portanto, não se trataria mais de eliminar, pela revolução, o mercado e o Estado, mas de domesticá-los para o desiderato de poderem contribuir com a emancipação, em acordo com a ação comunicativa.

Com fundamento na racionalidade comunicativa, Habermas não só pôde recuperar, da crítica radical do marxismo, como determinações emancipatórias, a ética, os direitos fundamentais, como, também, pôde pensar na domesticação do Estado, na figura do Estado de direito democrático, vinculado aos direitos fundamentais, bem como na domesticação do mercado, pela via o Estado de bem-estar social.

\section{Religião e bioética}

A religião entra pari passu na disputa com a ciência em relação a partir de quando se deve atribuir a dignidade humana ao ser humano, já que, nesse quesito, a ciência operaria no mesmo nível da religião, visto que as assunções ontológicas do naturalismo científico, que prefere o momento do nascimento, seriam tão triviais quanto as assunções metafísicas da religião, que prefere o momento da concepção. O ponto que interessa para Habermas, nessa disputa, é o que torna possível ambos os posicionamentos, a saber, o alto grau de continuidade da vida entre o seu início e o seu fim, seja qual for o momento escolhido para tal. Esta continuidade, para ele, diz contra a tentativa de tomar a ontologia como fundamento do normativo.

No texto O Futuro da Natureza Humana. A caminho da eugenia liberal? [2005], Habermas se posiciona contra uma eugenia liberal. Ele aponta para a miopia de tal posição, a qual residiria em conceber a manipulação genética como um aumento da liberdade de escolha, melhor seja dito, da liberdade de escolha sobre o corpo de um outro, não considerando as implicações sobre o terceiro envolvido, da mesma forma como um agente econômico, que concentra as atividades produtivas e de prestação de serviços de um setor da economia, avalia tal ato como exercício de sua liberdade de iniciativa. Nesse particular, Habermas imputa uma relação estreita entre a liberdade voltada à 
autorrealização e atitudes, disposições e propriedades condicionadas geneticamente ${ }^{12}$, de tal forma que a manipulação se torna condenável quando fixar [festlegen] a pessoa a um determinado plano de vida, quando restringir [einschränken] a liberdade para escolher uma vida própria ${ }^{13}$, o que implicaria a fixação [fixieren] às intenções de um terceiro, a qual seria irreversível para o sujeito, constituindo-se, portanto, em um paternalismo peculiar ${ }^{14}$. Desse modo, mesmo que, sob o ponto de vista da justiça distributiva, a eugenia pudesse ser justificada segundo o modelo liberal, como pensam Dworkin ${ }^{15}$ e Rawls ${ }^{16}$, ainda assim ela seria viciada por um tipo de assimetria entre o programador e o programado, incompatível com uma moral de sujeitos livres e iguais.

No texto Crer e saber publicado em O Futuro da Natureza Humana. A caminho da eugenia liberal? Habermas já chamara a atenção para o que a secularização incessante da sociedade pós-secular exige dos cidadãos crentes e não crentes, em um Estado constitucional democrático. Continuando essa linha de raciocínio, Entre naturalismo e religião: estudos filosóficos [2005] analisa duas tendências que desafiariam as convicções de se viver em uma ordem democrática: o naturalismo das imagens de mundo e a crescente influência da religião. Nesse sentido, o naturalismo alicerçar-se-ia

12 HABERMAS, Jürgen. Die Zukunft der menschlichen Natur. Auf dem Weg zu einer liberalen Eugenik? Frankfurt a. M.: Suhrkamp, 2001.p. 105.

13 HABERMAS, Jürgen. Die Zukunft der menschlichen Natur. Auf dem Weg zu einer liberalen Eugenik? Frankfurt a. M.: Suhrkamp, 2001.p. 105.

${ }^{14}$ HABERMAS, Jürgen. Die Zukunft der menschlichen Natur. Auf dem Weg zu einer liberalen Eugenik? Frankfurt a. M.: Suhrkamp, 2001.p. 109, 110.

15 Ver o texto Playing God em DWORKIN, Ronald. Sovereign Virtue: The Theory and Practice of Equality. Cambridge: Harvard University Press, 2000.

16 No item 17 de A Theory of Justice, The Tendency to Equality, Rawls trata da eugenia. Neste item ele quer demonstrar que o princípio da igual oportunidade não leva a uma sociedade meritocrática, pois, nesta, a "igualdade de oportunidades significa uma chance igual de deixar os menos afortunados atrás na disputa por influência e posição social”. Interessantemente, o tema da eugenia vem tratado nesse item, visto que o mesmo leva em consideração a distribuição natural dos talentos, justamente um dos aspectos centrais da eugenia, sendo tal distribuição vista, antes de tudo, como "a fact of nature". Uma possível política de eugenia é tratada por Rawls em conexão com o tema justiça social. Este tema da justiça social, no contexto da obra mencionada, encontra sua resolução no princípio da diferença. A partir de tal princípio, Rawls conclui não ser uma vantagem para os menos afortunados propor políticas que reduzam os talentos dos outros, pois pelo princípio mencionado, tais talentos podem ser usados para a vantagem comum. Assim, tendo em vista que talentos habilitam melhor a buscar planos de vida, as pessoas, na posição original, quereriam assegurar aos seus descendentes as melhores características genéticas, senão no sentido de uma eugenia positiva, ao menos para preservar um nível geral de talentos e evitar a difusão de defeitos graves. Portanto, Rawls avalia positivamente a eugenia, a partir do critério da justiça social, tal qual tratada pelo princípio da diferença. Ou seja, a eugenia é compatível com os princípios de justiça, sendo que mesmo os menos favorecidos podem querer que os outros escolham melhorar os talentos de seus descendentes, visto que eles próprios virão a ser indiretamente beneficiados por tais escolhas, na medida em que elas tenderão a aumentar o montante de riqueza social e, portanto, a beneficiar também os menos favorecidos, em razão do princípio da diferença. Em suma, Rawls conclui por uma política de eugenia liberal, a partir de sua teoria da justiça. 
em uma autocompreensão objetivada da pessoa, uma autoinstrumentalização, cujo paradigma encontrar-se-ia na área da biogenética. Tal autoinstrumentalização descuidaria dos aspectos normativos da modernidade, implicando falta de senso crítico, o que determinaria a necessidade de se estabelecer limites, tanto para a fé, quanto para o saber ${ }^{17}$. Nesse sentido, o pensamento crítico estabeleceria relações falibilistas, tanto com a ciência, quanto com a religião ${ }^{18}$.

Na disputa entre a naturalização do espírito e o impulso cognitivo à base das religiões, ele sustenta a tese hegeliana, "segundo a qual, as grandes religiões constituem parte integrante da própria história da razão" ${ }^{19}$. Ele concebe a religião como articulação da consciência do que falta ou do que falhou, preservando dimensões às quais o mundo secularizado pode provocar um dano irreparável. O ponto é que a manutenção da convicção nas determinações do Estado de direito democrático teria a sua fonte em uma solidariedade que não brotaria do próprio direito ${ }^{20}$, não podendo as doutrinas religiosas serem alijadas dessa empreitada . Em outras palavras, a formação da opinião e da vontade não pode ser feita coativamente ${ }^{21}$.

Há dois aspectos salientes na filosofia da religião de Habermas. Primeiro, de acordo com ele, Kant seria o arauto de uma filosofia da religião agnóstica que, no entanto, não consideraria a religião como supérflua. É nesse sentido que se deve entender a apropriação racional de conteúdos religiosos. Kant teria, portanto, operado uma apropriação salvadora de conteúdos religiosos nos limites da simples razão, de tal forma que ele poderia ser considerado exemplar da possibilidade de tradução racional de conteúdos cognitivos presentes na religião ${ }^{22}$. Segundo, no que diz respeito às implicações políticas da tradução da religião para argumentos publicamente aceitáveis, Habermas analisa se tal exigência de tradutibilidade por parte dos cidadãos religiosos se constituiria

17 HABERMAS, Jürgen. Entre naturalismo e religião: estudos filosóficos. Rio de Janeiro: Tempo Brasileiro, 2007, p. 9.

${ }^{18}$ HABERMAS, Jürgen. Entre naturalismo e religião: estudos filosóficos. Rio de Janeiro: Tempo Brasileiro, 2007, p. 13.

${ }^{19}$ HABERMAS, Jürgen. Entre naturalismo e religião: estudos filosóficos. Rio de Janeiro: Tempo Brasileiro, 2007, p. 13.

${ }^{20}$ HABERMAS, Jürgen. Entre naturalismo e religião: estudos filosóficos. Rio de Janeiro: Tempo Brasileiro, 2007, p. 9.

${ }^{21}$ HABERMAS, Jürgen. Entre naturalismo e religião: estudos filosóficos. Rio de Janeiro: Tempo Brasileiro, 2007, p. 12.

22 VOLPATO DUTRA, Delamar José. Tradução salvadora ou substituição progressiva: a leitura habermasiana da filosofia da religião de Kant. Kant e-Prints. V.9, p. 51-66, 2014.

\begin{tabular}{|l|l|l|l|l|}
\hline Rovista Qialectus & Ano 10 & n. 24 & Setembro - Dezembro 2021 & p. 54 - 66 \\
\hline
\end{tabular}


em uma exigência do Estado que feriria o requisito de sua neutralidade em relação a concepções abrangentes de bem.

\section{Referências:}

ADORNO, Th. W., HORKHEIMER, Max. Dialética do esclarecimento: fragmentos filosóficos. [Trad. G.A. de Almeida: Dialektiik der Aufklärung: Philosophische Fragmente]. Rio de Janeiro: Zahar, 1985 [1944].

ALMEIDA, Guido Antonio. Verdade e consenso. Revista Tempo Brasileiro. V. 98, 1989, p. 125-52.

APEL, Karl-Otto. Transformação da filosofia II: o a priori da comunidade de comunicação. [P. A. Soethe: Transformation der Philosophie. Band II]. São Paulo: Loyola, 2000 [1973].

ARAYA, Daniel. O que vem após a pandemia? Especialistas apostam no Renascimento Digital. https:/forbes.com.br/colunas/2020/04/o-que-vem-apos-a-pandemiaespecialistas-apostam-no-renascimento-digital/ [Acesso 19/04/2020].

CIRNE LIMA, Caros R. V. Sobre a contradição pragmática como fundamentação do sistema. Síntese. V. 18, n. 55, p. 595-616, 1991.

DE OLIVEIRA, Manfredo Araújo. Sobre a fundamentação. Porto Alegre: EDPUCRS, 1993.

DE OLIVEIRA, Manfredo Araújo. Sobre a fundamentação. Porto Alegre: EDPUCRS, 1993.

DWORKIN, Ronald. Sovereign Virtue: The Theory and Practice of Equality. Cambridge: Harvard University Press, 2000.

HABERMAS, Jürgen. Conhecimento e interesse. (Luiz Repa: Erkenntnis und Interesse). São Paulo: Editora UNESP, 2014 [1968].

HABERMAS, Jürgen. Da semântica formal à pragmática transcendental: a ideia original de Karl-Otto Apel. Ethic@. V. 19, N. 3, p. 487-517, 2020. [Dossiê O pensamento de Karl-Otto Apel. https://periodicos.ufsc.br/index.php/ethic/article/view/77949/45007].

HABERMAS, Jürgen. Die Zukunft der menschlichen Natur. Auf dem Weg zu einer liberalen Eugenik? Frankfurt a. M.: Suhrkamp, 2001.

HABERMAS, Jürgen. Entre naturalismo e religião: estudos filosóficos. Rio de Janeiro: Tempo Brasileiro, 2007.

HABERMAS, Jürgen. Mudança estrutural da esfera pública. [Denilson Luís Werle: Strukturwandel der Öffentlichkeit]. São Paulo: Editora UNESP, 2011 [1962, 1990]. 
HABERMAS, Jürgen. O discurso filosófico da modernidade. [Trad. Luiz S. Repa e R. NASCIMENTO: Der Philosophische Diskurs der Moderne]. Martins Fontes, 2000 [1985].

HABERMAS, Jürgen. O Futuro da Natureza Humana. A caminho da eugenia liberal? [Trad. Karina Jannini: Die Zukunft der menschlichen Natur. Auf dem Weg zu einer liberalen Eugenik?] São Paulo: Martins Fontes, 2004 [2001].

HABERMAS, Jürgen. Theorie des kommunikativen Handelns. (2 v.). Frankfurt am Main: Suhrkamp, 1981.

HEGEL, G. W. F. Linhas Fundamentais da Filosofia do Direito. 2. ed., [Trad. Paulo Meneses et. al.: Grundlinien der Philosophie des Rechts]. São Paulo, Recife, São Leopoldo: Loyola, Ed. UNICAP, Ed. UNISINOS, 2010 [1821].

HERRERO, F. Javier. A pragmática transcendental como "filosofia primeira". Veritas. V. 42, N. 4, p. 817-829, 1997.

HERRERO, Javier. A razão kantiana entre o logos socrático e a pragmática transcendental. Síntese. V. 18, N. 52, p. 35-57, 1991.

KANT, Immanuel. Princípios metafísicos da doutrina do direito. [Trad. J. Beckenkamp: Metaphysische Anfangsgründe der Rechtlehre]. São Paulo: Martins Fontes, 2014 [1797].

RAWLS, John. A Theory of Justice. [Revised Edition]. Oxford: Oxford University Press, 1999 [1971].

REPA, Luiz Sérgio. Reconstrução racional, argumento transcendental, fundamentação última: sobre o debate entre Habermas e Apel. Kriterion. N. 135, p. 741-758, 2016.

STEIN, Ernildo. Crítica da ideologia e racionalidade. Porto Alegre: Movimento, 1986.

STEINHOFF, Uwe. Against Equal Respect and Concern, Equal Rights, and Egalitarian Impartiality. IN.: Do all Persons Have Equal Moral Worth: On "Basic Equality" and Equal Respect and Concern. Oxford: Oxford University Press, 2015, p. 142-172.

STEINHOFF, Uwe. The Philosophy of Jürgen Habermas: A Critical Introduction. [K. Schöllner: Kritik der kommunikativen Rationalität: Eine Darstellung und Kritik der kommunikationstheoretischen Philosophie von Jürgen Habermas und Karl-Otto Apel]. Oxford: Oxford University Press, 2009.

VOLPATO DUTRA, Delamar José. Da revisão do conceito discursivo de verdade em "verdade e justificação". Ethic@, v. 2, n. 2, p. 219-231, 2003.

VOLPATO DUTRA, Delamar José. Tradução salvadora ou substituição progressiva: a leitura habermasiana da filosofia da religião de Kant. Kant e-Prints. V.9, p. 51-66, 2014. 